\title{
Development of new range of tops using origami technique
}

\section{Deepti Bhargava and Ekta Garg}

Received: 09.10.2020; Revised: 09.11.2020; Accepted: 26.11.2020

See end of the paper for authors' affiliations Deepti Bhargava

Department of Home Science, Banasthali University,

Banasthali (Rajasthan) India

Email : bhargava.deepti95@

gmail.com
ABSTRACT : The present study was undertaken by investigator to add new ideas for creating creative designs of tops. Thirty designs of tops with front bodice design, sleeve design and collar design using origami technique were developed and evaluated by the fifty respondents on the basis of uniqueness of design and aesthetic appeal. Design no. 4, 8, 11, 18 and 28 were selected for the development of prototypes. Prototypes were evaluated to know the consumer acceptance on the basis of certain parameters such as color, origami design and overall appearance by selected panel of respondents. It was found that all prepared prototypes were highly accepted by the respondents. The study has fulfilled its objectives with high performance of appreciation. All the tops were accepted by the consumers for the purchase and they were willing to wear.

- KEY WORDS: Origami, Garment designing, Clothing, Tops.

- HOW TO CITE THIS PAPER : Bhargava, Deepti and Garg, Ekta (2020). Development of new range of tops using origami technique. Asian J. Home Sci., 15 (2) : 372-375, DOI: 10.15740/HAS/AJHS/15.2/372375. Copyright@2020: Hind Agri-Horticultural Society. 